\title{
Schedule-cost Joint Management of Thermal Power Construction Project Based on Improved Earned Value Method
}

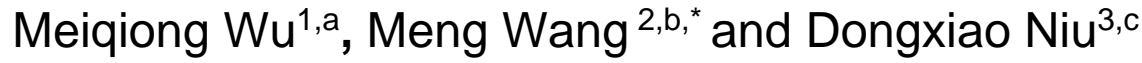 \\ ${ }^{1}$ School of Economics and Management, North China Electric Power University, Beijing, China \\ awumeiqiong92@163.com, bwmeng3007@163.coml, cniudx@ncepu.edu.cn
}

\begin{abstract}
Keywords: Trapezoidal fuzzy numbers, Earned value method, Risk factor, Schedule-cost performance evaluation.
\end{abstract}

\begin{abstract}
The risk of schedule and cost is the core part in the thermal power construction projects, while the traditional earned value method often ignores the existence of the risk in the schedule and cost analysis. This paper presents an improved earned value analysis method considering risk factors. In the method, the schedule and cost performance indicator is fuzzed based on trapezoidal fuzzy number, then introduces risk level coefficient to construct fuzzy earned value method considering risk factors based on the cut, and realize the integration of risk management and schedule cost analysis. Finally, one thermal power project is taken as an example to testify the practicability and validity of the improved model.
\end{abstract}

\section{Introduction}

In the traditional thermal power construction project management practice, the progress and cost are often controled relatively. With the increasingly fierce competition in the construction market of electric power projects, the mode of "project progress and cost control" has become the consensus of the industry. Earned value method can effectively control the progrss delay and cost overrun in thermal power construction by integrating the cost and schedule information, but its fundamental function is not risk control, even has nothing to do with risk control[1]. The thermal power plant construction project is in complex natural and social environment, its process often accompanies changes and a series of uncertainty, the uncertainty is affected by the scale, complexity, innovation and technology and so on, and it is restricted by the time, resources and environment. Therefore, the thermal power construction projects often have a higher risk, and the progress information is fuzzy, which makes it difficult to calculate the earned value parameters[2]

\section{Improved Earned Value Method Considered of Risk Factors}

\subsection{Method Principle}

2.1.1 Trapezoidal fuzzy number Give the universe $U$, set $A$ as the real set of $U$, so $u=[a, b, c, d]$ is a trapezoidal fuzzy number, and a,b,c,d are the real number of $A$. In particular, if $a=b=c=d, u$ will degenerate to a real number, if $b=c, u$ will become triangular fuzzy number [3]. The membership function is recorded as $u_{A}(x)$.

$$
u_{A}(x)= \begin{cases}0, & x<a \\ \frac{x-a}{b-a}, & a \leq x<b \\ 1, & b \leq x<c \\ \frac{d-x}{d-c}, & c \leq x<d \\ 0, & x \geq d\end{cases}
$$

In practical project, we use the fuzzy mathematics method to quantify the project progress because of the fuzziness of the project schedule data. The conversion method between the schedule metric fuzzy 
language and trapezoidal fuzzy number is shown in Table 1, which is based on the professional knowledge and project experience of senior project managers.

Table1 The corresponding relation table of fuzzy language and trapezoidal fuzzy number

\begin{tabular}{cc|cc}
\hline $\begin{array}{c}\text { linguistic value of } \\
\text { measurement }\end{array}$ & $\begin{array}{c}\text { trapezoidal fuzzy } \\
\text { number }\end{array}$ & $\begin{array}{c}\text { linguistic value of } \\
\text { measurement }\end{array}$ & $\begin{array}{c}\text { trapezoidal fuzzy } \\
\text { number }\end{array}$ \\
\hline Very little done & {$[0,0,0.1,0.2]$} & More than half done & {$[0.5,0.6,0.7,0.8]$} \\
Little done & {$[0.1,0.2,0.2,0.3]$} & Very much done & {$[0.7,0.8,0.8,0.9]$} \\
Less than half done & {$[0.2,0.3,0.4,0.5]$} & All done & {$[0.8,0.9,1.0,1.0]$} \\
half-done & {$[0.4,0.5,0.5,0.6]$} & & \\
\hline
\end{tabular}

2.1.2 Earned value method Earned value analysis is a kind of advanced project management control tool which can integrate schedule and cost. It is s set of technology based on schedule and cost joint monitoring method, after work breakdown, determine project schedule, progress and cost budget according to the progress plan of project, the allocation of cost budget, then conduct cost budget distribution and monitor performance progress of project. Due to the inconsistency of unit between schedule and cost, the method considers changing the time scale into currency scale on the basis of certain rules, and use the same set of monetary index system to measure the currency project schedule and cost performance, which can solve the difficultiy of sync check schedule and budget system[4].

(1) Basic parameters of earned value method

Planed value(PV) represents budgeted cost of planning work.In the light of the specific project schedule, the budget is used as the standard to calculate the total amount of work that should be done at a certain time, it reflects the amount of work that should be done on schedule, also known as budgeted cost for work scheduled(BCWS).

$$
P V=\text { planed } \text { workload } \times \text { budget unit price }
$$

Realized value, namely Earned Value (EV), is budgeted cost of performed work (BCWP).When inspect the implementation effect, BCWP reflects whether the project's progress is in accordance with the contract plan.

$$
E V=\text { completed } \text { workload } \times \text { budget } \text { unit price }
$$

The actual cost (AC) means the actual expenses of the project's completed workload (including completed and partially completed), which has nothing to do with the budget cost of the project, and it is also known as actual cost of work performed (ACWP).

$$
A C=\text { completed } \text { workload } \times \text { actual unit price }
$$

(2) Performance indexes of earned value method

Schedule performance index is used to measure the progress of the project, it reflects the ratio between the budgeted cost at a checkpoint and the budgeted cost of the planning work, which is the ratio of realized value to planned value. $S P I<1$ indicates the progress delay, or indicates progress ahead.

$$
S P I=\frac{E V}{P V}
$$

Cost performance index (CPI) is a specific index to measure the efficiency of project cost, it reflects the ratio between the budgeted cost at a checkpoint and actual cost, which is the ratio of earned value to actual costs. $C P I<1$ indicates overspend, or surplus.

\subsection{Improved Earned Value Method}

$$
C P I=\frac{E V}{A C}
$$

2.2.1 Earned value method based on trapezoidal fuzzy number In order to solve the problem that the total amount of work is unknown or uncertain, we can adopt fuzzy earned value method in the project with poor controllability. This paper improves earned value analysis method based on trapezoidal fuzzy number. 
Assuming that the earned value of a job $i$ is $E V_{i}$, the fuzzy EV $\tilde{E V}$, of the work is as follows:

$$
\tilde{E V_{i}}=\tilde{K}_{i} \times P V=\left[E_{11}, E_{2 i}, E_{3 i}, E_{4 i}\right]
$$

$K_{i}$ is the fuzzy completion percentage of the work $i$, which is adopted by the trapezoidal fuzzy number shown in Table 1, its module number is shown as follows:

$$
\tilde{K}_{i}=\left[a_{1 i}, a_{2 i}, a_{3 i}, a_{4 i}\right]
$$

Then the total fuzzy earned value of every measurement cycle can be calculated by accumulating the fuzzy earned value $\tilde{E V}$, of each activity. Assuming that a project has $i$ jobs, the total fuzzy earned value $\tilde{E V}$ is calculated as:

$$
\tilde{E V}=\sum_{i=1}^{n} \tilde{E V_{i}}=\left[\sum_{i=1}^{n} \tilde{E V_{1 i}}, \sum_{i=1}^{n} \tilde{E V_{2 i}}, \sum_{i=1}^{n} \tilde{E V_{3 i}}, \sum_{i=1}^{n} \tilde{E V}_{4 i}\right]=\left[E_{i l}, E_{2 i}, E_{3 i}, E_{4 i}\right]
$$

Thus, trapezoidal fuzzy numbers of SPI and CPI are shown as follows:

$$
\begin{aligned}
& S P I=\frac{\tilde{E V}}{P V}=\left[\frac{E_{1}}{P V}, \frac{E_{2}}{P V}, \frac{E_{3}}{P V}, \frac{E_{4}}{P V}\right] \\
& C P I=\frac{\tilde{E V}}{A C}=\left[\frac{E_{1}}{{ }_{A C}}, \frac{E_{2}}{A C}, \frac{E_{3}}{A C}, \frac{E_{4}}{A C}\right]
\end{aligned}
$$

2.2.2 Fuzzy earned value method considering risk factors The traditional earned value method reflects the project performance through comparing the schedule cost performance index with value 1 , and the new fuzzy index is similar, also compared with value 1 . Due to the new performance index is fuzzy number, so we need using fuzzy number ranking method. This paper adopts the $\alpha$ cut Fuzzy Number Ranking method [5], which is shown by comparing interval numbers of two fuzzy numbers. The $\alpha$ cut set of trapezoidal fuzzy numbers is:

$$
\tilde{A}=[a+\alpha(b-a), d-\alpha(d-c)] 0 \leq \alpha \leq 1
$$

This paper will define $\alpha$ as the comprehensive risk level coefficient to measure the various factors in the process of project construction impact on the construction schedule and cost, then built fuzzy EV method considering risk factors so as to realize the effective integration of risk management and EV analysis. So the fuzzy schedule cost performance index considering risk

\begin{tabular}{|c|c|c|c|}
\hline \multicolumn{2}{|r|}{${ }^{a} S P I$} & \multicolumn{2}{|r|}{$\widetilde{\sim} \widetilde{C P I}$} \\
\hline Value & Evaluation result & value & evaluation result \\
\hline${ }^{\alpha} S P I<1$ & Progress delay & $\tilde{a} \widetilde{C P I}<1$ & Cost overrun \\
\hline${ }^{\circ} S P I=1$ & Meet the requirement & $\tilde{a} \widetilde{C P I}=1$ & Meet the requirement \\
\hline${ }^{a} S P I>1$ & Progress ahead & ${ }^{a} \tilde{C P I}>1$ & Cost surplus \\
\hline
\end{tabular}
factors is as follows:

$$
\begin{aligned}
& { }^{\alpha} S P I=\frac{E_{4}}{P V}-\alpha\left(\frac{E_{4}-E_{3}}{P V}\right)=\frac{E_{4}-\alpha\left(E_{4}-E_{3}\right)}{P V} \\
& { }^{\alpha} C P I=\frac{E_{4}}{A C}-\alpha\left(\frac{E_{4}-E_{3}}{A C}\right)=\frac{E_{4}-\alpha\left(E_{4}-E_{3}\right)}{A C}
\end{aligned}
$$

Table 2 shows evaluation criteria of fuzzy schedule cost performance index considering risk.

Table 2 the evaluation criteria of fuzzy schedule cost performance index

\section{Empirical Research}

Jixi B plant $2 \times 300 \mathrm{MW}$ coal gangue cogeneration project is the"large-scale environmental protection energy-saving demonstration project" constructed by Datang power company, which collects coal gangue, heating and power generation comprehensive development and utilization integration. This project launched its construction in 2009, Milestone Schedule plan 1\# unit's total duration was 25 
months, 2\# was 28 months. The dynamic gross investment of the final accounts for the completed project was 3.1 billion RMB, including capital 0.6 billion RMB and bank loans of 2.5 billion RMB.

The thermal power plant construction project set end of month as monitoring points to count the plan value and actual cost. The total project is divided into three phases, respectively, 1-10 months, 11-21 months and 22-28 months after the beginning. This paper adopts fuzzy EV analysis in the first phase. Specific planning value, actual costs and actual progress are shown in table 3.

Table 3 The plan value, actual costs and actual progress of the first phase

\begin{tabular}{cccc}
\hline Date & $P V$ (hundred million RMB) & $A C$ (hundred million RMB) & Percentage of completion \\
\hline 1 & 1.85 & 1.85 & All done \\
2 & 3.05 & 2.95 & All done \\
3 & 3.95 & 3.95 & Very much done \\
4 & 4.8 & 4.75 & Very much done \\
5 & 5.7 & 5.61 & All done \\
6 & 6.8 & 6.61 & More than half done \\
7 & 7.55 & 7.41 & More than half done \\
8 & 8.6 & 8.41 & Very much done \\
9 & 9.8 & 9.51 & Less than half done \\
10 & 10.89 & 10.51 & Very much done \\
\hline
\end{tabular}

According to the monitoring point data and formula (2-7), we can calculate the fuzzy earned value of each monitoring point, and the summary data are shown in table 4.

Table 4 Fuzzy earned value summary sheet for each monitoring point

\begin{tabular}{ccccc}
\hline Date & $\begin{array}{c}P V(\text { hundred million } \\
\text { RMB })\end{array}$ & $K_{i}$ & Trapeze fuzzy numbers & $\tilde{E V_{i}}$ \\
\hline 1 & 1.85 & All done & {$[0.8,0.9,1.0,1.0]$} & {$[1.48,1.67,1.85,1.85]$} \\
2 & 3.05 & All done & {$[0.8,0.9,1.0,1.0]$} & {$[2.44,2.75,3.05,3.05]$} \\
3 & 3.95 & Very much done & {$[0.7,0.8,0.8,0.9]$} & {$[2.77,3.16,3.16,3.56]$} \\
4 & 4.8 & Very much done & {$[0.7,0.8,0.8,0.9]$} & {$[3.36,3.84,3.84,4.32]$} \\
5 & 5.7 & All done & {$[0.8,0.9,1.0,1.0]$} & {$[4.56,5.13,5.70,5.70]$} \\
6 & 6.8 & More than half done & {$[0.5,0.6,0.7,0.8]$} & {$[3.40,4.08,4.76,5.44]$} \\
7 & 7.55 & Very much done & {$[0.7,0.8,0.8,0.9]$} & {$[5.29,6.04,6.04,6.80]$} \\
8 & 8.6 & Very much done & {$[0.7,0.8,0.8,0.9]$} & {$[6.02,6.88,6.88,7.74]$} \\
9 & 9.8 & More than half done & {$[0.5,0.6,0.7,0.8]$} & {$[4.90,5.88,6.86,7.84]$} \\
10 & 10.89 & All done & {$[0.8,0.9,1.0,1.0]$} & {$[8.71,9.80,10.89,10.89]$} \\
\hline
\end{tabular}

Assuming that the thermal power construction project risk coefficient is $\alpha=0.6$. Then we can be calculate the fuzzy schedule cost performance indexes considering the risk factors according to the $\mathrm{Eq}(2-12)$, the specific results are summarized in table 5. 
Table 5 The evaluation resultsof fuzzy schedule cost performance considering risk factor

\begin{tabular}{clccc}
\hline Date & ${ }^{\alpha}{ } S P I$ & Evaluation results & ${ }^{\alpha}{ }_{C P I}$ & Evaluation results \\
\hline 1 & $1=1$ & Meet the requirement & $1=1$ & Meet the requirement \\
2 & $1=1$ & Meet the requirement & $1.03>1$ & Cost overrun \\
3 & $0.84<1$ & Progress delay & $0.9<1$ & Cost surplus \\
4 & $0.84<1$ & Progress delay & $0.91<1$ & Cost surplus \\
5 & $1=1$ & Meet the requirement & $1.02>1$ & Cost overrun \\
6 & $0.74<1$ & Progress delay & $0.82<1$ & Cost surplus \\
7 & $0.84<1$ & Progress delay & $0.92<1$ & Cost surplus \\
8 & $0.84<1$ & Progress delay & $0.92<1$ & Cost surplus \\
9 & $0.74<1$ & Progress delay & $0.82<1$ & Cost surplus \\
10 & $1=1$ & Meet the requirement & $1.04>1$ & Cost overrun \\
\hline
\end{tabular}

According to the evaluation results in the table 5, the construction schedule of the first stage's first two months basically meet the baseline plan, the third and fourth months present progress delays in a certain degree. Then in fifth month, the progress catchs up with the initial plan by investing some man power, material and financial resources, from sixth to ninth months, the schedule has been delayed, progress and to return to normal but by effort oflast months.

In addition, according to the evaluation results of the cost performance indicators, other months are basically saving except the first, fifth and tenth in the first phase.

\section{Summary}

In terms of the problem that the thermal power construction project can not get the project schedule accurately because of the complicated construction process, the measurement of earned value by fuzzy earned value method is the first step in the implementation of earned value management. In this paper, the fuzzy method is used to quantify the project progress, and introducts the risk coefficient based on the idea of $\alpha$ cut sorting to construct the fuzzy earned value analysis method considering risk factors. Then the model was used to evaluate the cost schedule of Jixi thermal power construction project. Meanwhile, this paper verified the feasibility of the method and realized the integration of risk management and schedule cost analysis.

\section{References}

[1] H. Zhao, Y. M.Feng, The first exploration of the earned value management and risk management. Shanxi Architecture, vol.36, pp.227-228, 2009.

[2] G. L.Wang, Research on the application of earned value method in thermal power construction project, North China Electric Power University (Beijing), 2008.

[3] W. S. Liu, Z. Q Wu, T. J. Cui, Research on optimal selection method of continuous coordinate mining plan based on trapezoidal fuzzy number, Journal of Natural Disasters, 2016.

[4] Janeska M, Zdraveski D, Angeleski M, Importance of raened vavue method (EVA) in the performance analysis of projectsI, Annals of 'Constantin Brancusi' University of Targu-Jiu. Economy, vo1.1, 2016. 